www.jmscr.igmpublication.org

Index Copernicus Value: 79.54

ISSN (e)-2347-176x ISSN (p) 2455-0450

crossref DOI: https://dx.doi.org/10.18535/jmscr/v7i5.26

\title{
Sinonasal Angiomatous Polyp: A Rare Occurrence A Case Series of 2 Cases \& Review
}

\author{
Authors \\ Dr S K Kashyap ${ }^{1}$, Ishan Dixit ${ }^{2}$, Mohd Tausif ${ }^{3}$, Shikha Chaudhary ${ }^{4}$ \\ ${ }^{1}$ Professor HOD, Department of ENT, MLB Medical College Jhansi \\ ${ }^{2}$ JR3, Department of ENT, MLB Medical College Jhansi \\ ${ }^{3,4}$ JR2, Department of ENT, MLB Medical College Jhansi
}

\begin{abstract}
Sinonasal Angiomatous Polyp a subtype of sinonasal polyp, is a benign and non-neoplastic lesion rarely reported in the literature. We recently came across a middle aged female who presented to us with right sided nasal blockage with episodic bleeding for 6 months. On nasal endoscopy polypoidal nasal mass was seen occupying the nasal cavity, maxillary sinus and the nasopharyngeal region with bleeding areas. Histopathology confirmed to be as Sinonasal Angiomatous polyp. Here, we are discussing the presentations of the sinonasal angiomatous polyp, its diagnosis and the line of management for the patient.
\end{abstract}

\section{Introduction}

Sinonasal angiomatous polyp a subtype of sinonasal polyp, is a benign and non neoplastic lesion rarely reported in the literature ${ }^{[1]}$ Sinonasal angiomatous polyp can be cured by simple conservative surgical excision, and rarely relapses. Computed tomography examination has become one of the preferred imaging methods for evaluating sinonasal lesions. However, only a few studies on SAP suggested that CT findings lack specificity to identify this lesion, even with the administration of contrast medium.

\section{Case Report}

A 32 year old female came to our opd with complaints of episodic nasal bleeding from rt side of nose with nasal blockage and headache for 6 months. On evaluation patient gave history of similar complaints for which she underwent surgical excision 5yrs back. A detailed clinical examination including nasal endocopy was done which revealed a nasal mass on rt side which was red and fleshy bleed profusely on probing. Biopsy was taken and send for histopathology as malignancy was suspected. Biopsy report was inconclusive.

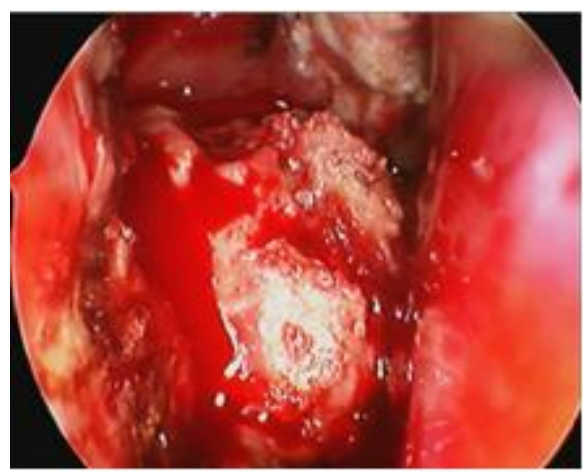

Fig 1 Endoscopic picture of the nasal part of mass (bleeding can be seen from the mass) 


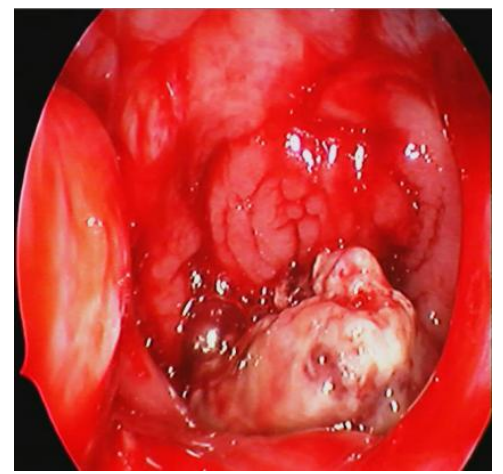

Fig 2 nasopharyngeal part of mass

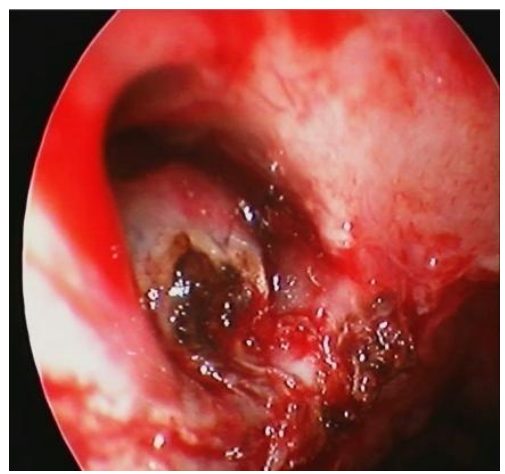

Fig 3 maxillary part of mass

CECT was done which showed a heterogenous mildy enhancing lesion with varaiable contrast uptake it also showed the mass occupying whole of maxillary sinus posterior part of nasal cavity and blocking osteomeatal complex.
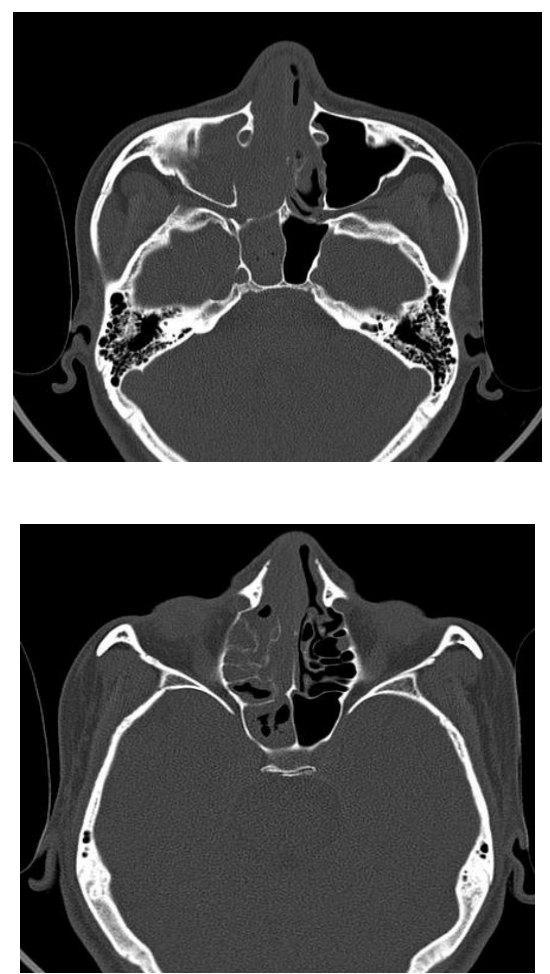

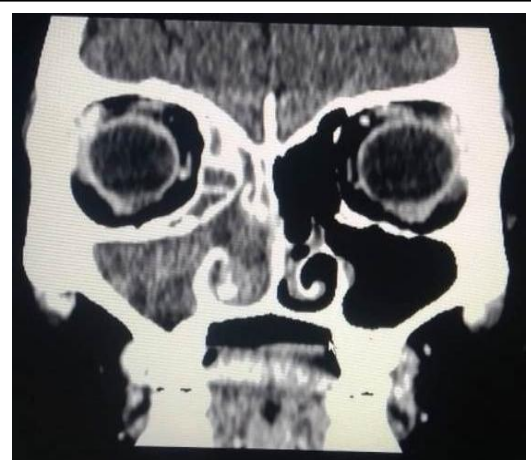

Fig 4,5,6- CT images of the mass

She was planned for endoscopic surgical excision the mass was attached to 3 places viz. anterioinferior wall of maxillary sinus, posterior part of nasal septum, posteriosuperior part of maxillary opening. All the attachements of the mass were cauterized to reduce the vascularity and blood loss during the operative procedure. All the attachments were cut and as the mass was huge and was extending to choanae so the mass was pushed downwards \& removed through oral cavity. A part of mass which was left in the maxillary sinus was also removed endoscopically the mass were send for histopathology and it showed the lesion was covered by ciliated columnar epithelium; hemorrhagic necrosis and cellulose effusion were also seen along with expansive and congested thin-walled blood vessels in the lesion, with edematous stroma infiltrated by many inflammatory cells which was reported to be a sinonasal angiomatous polyp.

\section{Case 2}

A 24 year old female came to our opd with 2 episodes of nasal bleeding for opast 1 month, nasal blockage for 4 months and headache for 4 months. on detailed history and examination including nasal endoscopy was done which revealed a nasal mass on right side which bleed on probing. Biopsy was taken and send for histopathology and came out as inflammatory polyp.

CECT was done which showed a heterogenous mildly enhancing lesion with variable contrast uptake it also showed the mass present in 
maxillary sinus and posterior part of nasal cavity but not erxtending to nasopharynx.

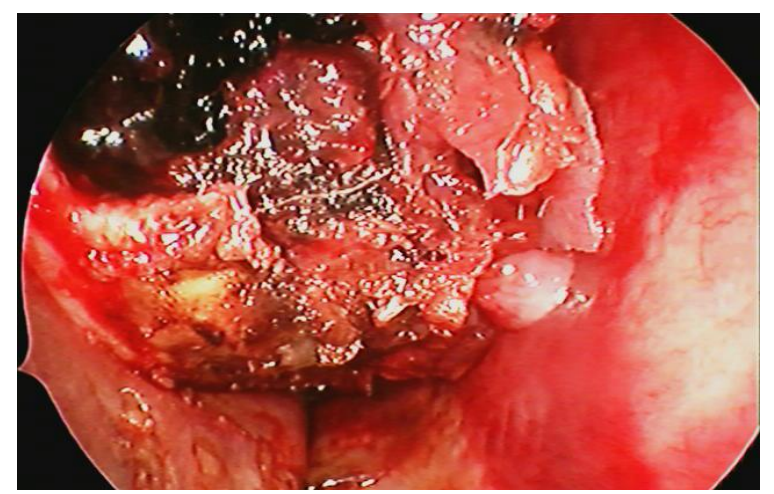

Fig1 endoscopic picture of the mass

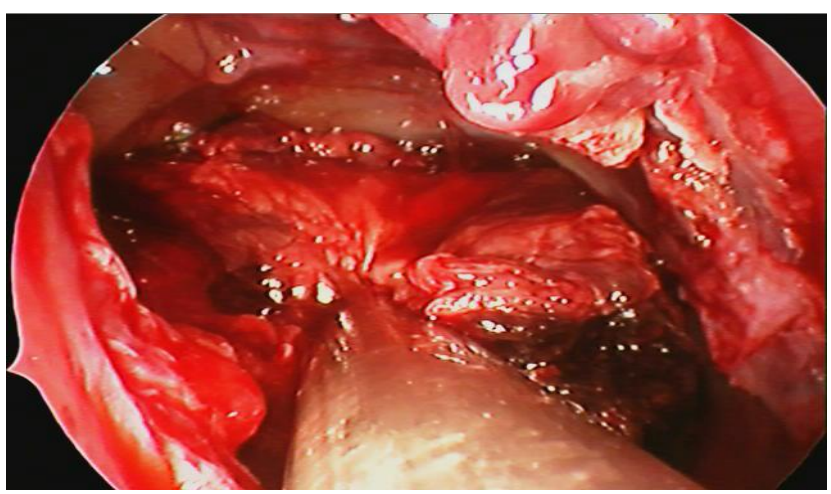

Fig2 mass cleared from maxillary sinus

She was planned for endoscopic surgical excision the mass was attached to 2 places viz. posterior wall of maxillary sinus, posterior part of nasal septum. All the attachments of the mass were cauterized to reduce the vascularity and blood loss during the operative procedure. All the attachments were cut and the mass was removed through oral cavity. A part of mass which was left in the maxillary sinus was also removed endoscopically the mass were send for histopathology and it showed the lesion was covered by ciliated columnar epithelium; hemorrhagic necrosis and cellulose effusion were also seen along with expansive and congested thin-walled blood vessels in the lesion, with edematous stroma infiltrated by many inflammatory cells which was reported to be a sinonasal angiomatous polyp.

\section{Discussion}

Sinonasal polyps are classified into several types: edematous, glandular, fibrous, cystic, and angiectatic or angiomatous. The nomenclature of sinonasal angiomatous polyp is not consistent in the literature and includes granuloma telangiectaticum, vascular granuloma, cavernous hemangioma, pseudotumor, hemorrhagic necrotic polyp, and angioectatic or angiomatous polyp. ${ }^{[3,4]}$ In our hospital, the diagnoses were inconsistent and we enrolled the patient according to the detailed pathological description given earlier, which shared common clinical and radiological findings.

Several hypotheses for the pathogenesis of SAPs have been reported in the literature. One of that is, sinonasal angiomatous polyp is derivative of an antrochoanal polyp. ${ }^{[5],}{ }^{[2]}$ Compression of the vessels results in vascular dilatation, stasis, edema, and ischemia of the polyp. This can also cause venous infarction, thrombosis formation, and subsequent neovascularization and fibrosis of the polyp, whereupon the term "angiomatous" was proposed. ${ }^{[1,6]}$

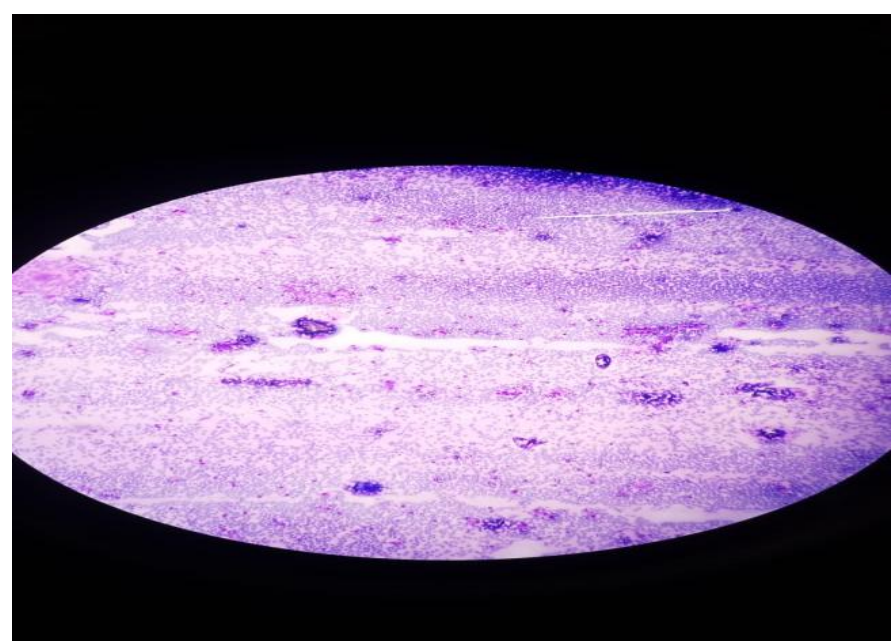

Histopathologic photomicrograph of sinonasal angiomatous polyp

We support this theory because in our patient's nasal mass originated from the maxillary sinus, involving the osteomeatal complex, and extended into the nasal cavity, with involvement of the posterior choana and nasopharynx, without any bony destruction. 
The CT findings in our patient was not specific. The typical features of sinonasal angiomatous polyp are expansile mass in the sinus with bony wall destruction and remodeling. Some benign lesions can also exhibit bony erosion on computed tomography such as inverted papilloma and haemangioma $^{[6]}$. Ding et al have reported that the vessel-like marked enhancement and progressive enhancement on two-phase helical CT scans are characteristic features of SAP, which could be a useful tool to make more confirmative diagnosis before surgery. Bony destruction although raises suspicion for carcinoma it always is never diagnostic for malignancy. In an adult patient the findings of unilateral epistaxis accompanied with nasal obstruction will cause the clinician and radiologist to commit mistake and go in favour of a malignant lesion.

\section{Conclusion}

SAP is a rare variant of sinonasal polyp that mimics inverted papilloma, juvenile angiofibroma, and malignant tumor in its clinical and radiological aspects. The patient in our study presented with unilateral nasal obstruction, rhinorrhea, and epistaxis. The CT images showed expansile sinonasal-occupying lesions with obstructive sinusitis in adjacent sinus cavities.

A biopsy to confirm the diagnosis before surgical treatment is helpful for diagnosis and further management, whether preoperatively or intraoperatively. For patients with Sinonasal angiomatous polyp, the treatment of choice is to completely remove the polypoid mass and restore the drainage system of all sinus cavities.

\section{Bibliography}

1. De Vuysere S, Hermans R, Marchal G. Sinochoanal polyp and its variant, the angiomatous polyp: MRI findings. Eur Radiol. 2001;11(1):55-58.
2. Batsakis JG, Sneige N. Choanal and angiomatous polyps of the sinonasal tract. Ann Otol Rhinol Laryngol. 1992;101 (7):623-625.

3. Dai LB, Zhou SH, Ruan LX, Zheng ZJ. Correlation of computed tomography with pathological features in angiomatous nasal polyps. PLoS One. 2012;7(12):e53306.

4. Ceylan A, Asal K, Celenk F, Uslu S. An angiomatous nasal polyp: a very rare variant of sinochoanal nasal polyps. BENT. 2007;3(3):145-147.

5. Dai LB, Zhou SH, Ruan LX, Zheng ZJ. Correlation of computed tomography with pathological features in angiomatous nasal polyps. PLoS One. 2012;7(12):e53306.

6. Zou J, Man F, Deng K, Zheng Y, Hao D, $\mathrm{Xu} \mathrm{W}$. CT and MR imaging findings of sinonasal angiomatous polyps. Eur J Radiol. 2014;83(3):545-551. 